Res Social Adm Pharm. 2012 Dec 4. pii: S1551-7411(12)00348-8.

doi: 10.1016/j.sapharm.2012.11.003. [Epub ahead of print]

\title{
Community pharmacy in Australia: A health hub destination of the future.
}

\begin{abstract}
Background: Rates of chronic illness are rising in Australia and as medications are frequently used in the management of a range of chronic conditions, community pharmacists are in an ideal position to better assist these consumers. There is currently limited information as to how pharmacy can do this from the perspective of consumer health organizations, health advocates and professional support organizations.
\end{abstract}

Objectives: To explore new roles, opportunities and any associated barriers for community pharmacy to better assist consumers with chronic illnesses.

Methods: Representatives of non-government consumer health organizations $(n=10)$ were interviewed from the key health priority areas emphasised by the Australian government. Health advocates $(n=3)$, innovative health care professionals $(n=4)$ and representatives of health care professional organizations $(n=4)$ from pharmacy and medicine also participated. Interviews were analysed via thematic analysis.

Results: Twenty-one in-depth interviews were conducted. The core finding was the potential for community pharmacies to become a health hub destination, whereby pharmacy staff assist consumers with chronic conditions to: navigate the health system (e.g., provide information on support services), manage their medications, and provide health advocacy. Participants expressed their concern that consumers may not be aware of the breadth of the pharmacist's expertise and that further collaboration is needed with non-government consumer health organizations and other health providers. Emphasis was placed on the improvement of the pharmacist's current role, particularly in the area of medication advice and accessibility, with the current pharmacy remuneration model identified as a barrier to becoming a health hub destination. 
Res Social Adm Pharm. 2012 Dec 4. pii: S1551-7411(12)00348-8.

doi: 10.1016/j.sapharm.2012.11.003. [Epub ahead of print]

Conclusion: The eventual progression towards a health hub destination was seen to be important to better assist consumers with chronic conditions. This focuses on a more proactive approach to care encompassing simple advice, referrals to consumer health organizations and ultimately, health advocacy. However, further research is required into how community pharmacy can become a health hub given that this is a new concept and there are existing professional barriers. 
Res Social Adm Pharm. 2012 Dec 4. pii: S1551-7411(12)00348-8.

doi: 10.1016/j.sapharm.2012.11.003. [Epub ahead of print]

\section{Introduction}

The increasing prevalence of chronic illnesses is of global significance, causing an estimated 36 million deaths in 2008. ${ }^{1}$ Given that the majority of Australians reported the presence of one or more long term conditions in $2007-2008^{2}$, and health expenditure exceeded $\$ 100$ billion for the first time in this period, ${ }^{3}$ appropriate and effective delivery of health care for consumers with chronic illness is of paramount importance. Currently, many Australians regularly visit their community pharmacy for advice and to obtain medication to treat or relieve symptoms or prevent the progression of chronic conditions. As community pharmacy has been viewed as highly accessible, ${ }^{4,5}$ pharmacists clearly have a role to play in improving the health care for these consumers. ${ }^{6}$ In particular, the pharmacy profession has been shifting towards care delivery that is more patient-centered, ${ }^{7}$ with pharmacists in many countries providing management programs for chronic conditions including asthma, arthritis, mental illness, diabetes, cardiovascular health and osteoporosis. ${ }^{8}$ In Australia, whilst community pharmacists are still focused on dispensing medication, they have also integrated a range of professional services into their practice such as medication reviews and diseasespecific management programs. ${ }^{9}$ The expansion of the pharmacist's role is strongly advocated by two peak pharmacy organizations in Australia, ${ }^{5,10}$ and the suitability of pharmacists to provide professional services in the primary care setting is well articulated in the literature. ${ }^{4}{ }^{11}$ Previous studies have also shown that the provision of disease-specific services in community pharmacy is generally well received by users, ${ }^{12}$ due to the accessibility and convenience of these services. ${ }^{13}$

Another key source of support for consumers with chronic conditions is consumer health organizations (e.g., Parkinson's Australia, Alzheimer's Australia). These organizations 
Res Social Adm Pharm. 2012 Dec 4. pii: S1551-7411(12)00348-8.

doi: 10.1016/j.sapharm.2012.11.003. [Epub ahead of print]

provide psychosocial support and a range of informational resources to better enable consumers and their carers to manage their conditions. ${ }^{14}$ These groups are in a unique position to gain further understanding of what their consumer members need from the health system, including community pharmacy. ${ }^{15}$ Furthermore, these organizations may also refer their members to community pharmacy for additional services. Therefore, it would be valuable to seek their opinions of the role that community pharmacy can play to better assist the consumers they represent. However, there is limited information on the perceived role of community pharmacy from the perspective of consumer health organizations. One Australian report explored the views of consumer health organizations in relation to consumers' experiences, expectations and needs of community pharmacy. Personalised service from the pharmacist and greater provision of medication information were key recommendations from the focus groups. ${ }^{16}$ Similarly, professional organizations, government bodies and consumer health organizations identified the need for improvements in relation to pharmacist engagement within the community, the level of privacy and provision of written and verbal information to support consumers. ${ }^{16}$ Another Australian project reported that 'community pharmacy may not be initially seen as part of the central strategy by patient support organizations. ${ }^{, 17}$

Despite the evolving role of the pharmacist in chronic disease management, they are underutilised as health care professionals. ${ }^{18}$ Although the reasons for underutilisation are complex, one very important issue is the lack of consumer awareness of the breadth of skills pharmacists have. ${ }^{19,20}$ Research suggests that consumers perceive the pharmacist's primary role as medication providers, ${ }^{7,12}$ or mainly view the community pharmacy as a place to purchase quality medications. ${ }^{12}$ One Australian study has also corroborated the belief that the core function of a pharmacy is the provision of medicine and advice, highlighting the limited 
Res Social Adm Pharm. 2012 Dec 4. pii: S1551-7411(12)00348-8.

doi: 10.1016/j.sapharm.2012.11.003. [Epub ahead of print]

awareness of consumers and consumers advocates (e.g., support group representatives) about the services offered by community pharmacy. ${ }^{17}$ There is clearly a misalignment between how consumers (and their advocates) view the pharmacist's role and what pharmacists can actually offer.

Given that the Australian government has emphasised the management of chronic illness as a strategic priority area, ${ }^{21}$ there is a significant opportunity for community pharmacy to be of greater assistance to these consumers. However, considering the lack of knowledge about the role of community pharmacy, it is necessary to first understand the perspectives of those who will influence the utilisation of such services in the future (i.e., non-government consumer health organizations, health advocates and health care professional organizations). Consequently this raises the question: how can community pharmacy better assist consumers with chronic illness to manage their condition(s)?

The aim of this exploratory study was to identify the views of key stakeholders (i.e., individuals representing non-government consumer health organizations and health advocates) with respect to the role of community pharmacy in supporting consumers with chronic illness(s). The study also sought to identify the opportunities and barriers for community pharmacy in chronic illness management from the viewpoints of health care professional organizations from pharmacy and medicine. Furthermore, the themes identified will be used to develop an interview guide for a much larger study involving consumers with chronic illness(s) and carers.

\section{Method}

Study design 
Res Social Adm Pharm. 2012 Dec 4. pii: S1551-7411(12)00348-8.

doi: 10.1016/j.sapharm.2012.11.003. [Epub ahead of print]

A list of non-government consumer health organizations, health care professional organizations, health advocates and innovative health care professionals were obtained by the following methods: prior researcher knowledge from working in the health sector, discussion with a Reference Group comprising of members with knowledge in the field and recommendations from study participants. Additional participants were also identified during the completion of the in-depth interviews via a snowball sampling strategy. As both nongovernment consumer and professional organizations are nationally recognized, additional contact details were obtained from the internet. Innovative health professionals were identified as leaders in their field who also had extensive experience in organizational and pharmacy practice.

Consumer health organizations were purposively selected ${ }^{22}$ as representing the following disease groups: arthritis, asthma, diabetes, cancer, mental health and cardiovascular health. These health areas have been identified as high priority by the Australian Government as they contribute to significant morbidity, mortality or both. ${ }^{23} \mathrm{Up}$ to two people participated from each selected organization to facilitate exploration of different perspectives within the organization. These perspectives included policy development (e.g. CEO/board member) or program implementation (e.g. program officer). Health advocates were drawn from organizations and innovative individuals that supported culturally and linguistically diverse (CALD) communities, carers and health consumers. Health care professionals were selected from peak organizations representing medicine and pharmacy.

Researchers initially contacted the CEO of each organization (via phone and email) to identify if the organization would be interested in participating in the study and the individual(s) that would best represent their views/interests. In some instances, individuals were contacted to participate directly (e.g., Health advocates and individuals recommended by the Reference Group and study participants). 
Res Social Adm Pharm. 2012 Dec 4. pii: S1551-7411(12)00348-8.

doi: 10.1016/j.sapharm.2012.11.003. [Epub ahead of print]

Semi-structured interviews were used, giving stakeholders the opportunity to express their opinion(s) and experiences ${ }^{24}$, enabling exploration of a number of areas: concerns related to the management of a chronic illness and medication use that community pharmacy could assist with, views of the current and future role(s) of community pharmacy and potential barriers in developing these role(s). An interview guide (Table 1) was developed after reviewing the literature, piloted with a past senior member of a consumer health organization, discussed and further refined by the project team prior to the commencement of the interviews. The interview guide was further modified as the interviews progressed to enable exploration of new information.

\section{Procedure}

On confirmation of an individual's verbal agreement to participate, the study information sheet and interview guide were emailed to each key stakeholder. Two researchers (SM, AS) from different health backgrounds (pharmacy and public health) conducted semistructured interviews with participants between January and March 2012. Informed consent was obtained from all participants prior to the commencement of the interview and their confidentiality was assured. All interviews were recorded and transcribed verbatim by the interviewers (SM and AS), who also conducted peer-debriefing sessions. This started an informal coding process, enabling the research team to familiarise themselves with the data and inform changes to the interview guide. The study received ethical approval from a University Human Research Ethics Committee (PHM/12/11/HREC).

\section{Data analysis}

The interview questions pertaining to this study was independently analysed by an experienced researcher (SM) using thematic analysis, a common approach used to analyse 
Res Social Adm Pharm. 2012 Dec 4. pii: S1551-7411(12)00348-8.

doi: 10.1016/j.sapharm.2012.11.003. [Epub ahead of print]

qualitative data in health care research. ${ }^{25}$ The researcher had a pharmacy background, however tried to utilise an inductive approach by not engaging with the literature prior to data analysis. ${ }^{26}$ As the study aimed to explore an under-researched area, a semantic approach to thematic analysis was used to provide a description of the entire data set. ${ }^{26}$ This method of analysis would also enable the researchers to identify important themes for future exploration. Once familiar with the data from reading and re-reading the transcripts, the researcher used the electronic qualitative data analysis package QSR NVIVO $9^{\odot}$ to organise the data into broad codes. Further categorisation of these codes occurred in the next stage of the analysis. To ensure credibility and trustworthiness of the data, in-depth discussions were undertaken with two other researchers (AS, FK) around the analysis process and findings, thus verifying the researcher's judgement. Written transcripts were also returned to some participants to ensure that their perspectives were truly represented. Interviews continued until data saturation was achieved (i.e. no new themes were identified). Although the participants were from different organisations, they all came from a health background and were advocates for better health care. In this respect, participants could be classified as a relatively homogenous group. Furthermore, rich data was obtained from each interview, which facilitated reaching data saturation. ${ }^{27}$ Data for all participants were analysed with the following identifiers used for participant quotations: a non-government consumer health organization representative $(\mathrm{CHO})$, innovative health care professional/representative of a health care professional organization (HCP) or a health advocate/consultant (HA).

\section{Results}

\section{Study participants}


Res Social Adm Pharm. 2012 Dec 4. pii: S1551-7411(12)00348-8.

doi: 10.1016/j.sapharm.2012.11.003. [Epub ahead of print]

Participants $(n=21)$ included three board members (policy development) and seven personnel (program implementation) from non-government consumer health organizations $(\mathrm{CHO})$, with two of these participants representing a culturally and linguistically diverse (CALD) organization. Three consumer health advocates (HA) were recruited including two consumer health organization representatives and an individual not aligned with a particular organization. Three representatives of pharmacy organizations, a representative from a medical organization and four innovative practitioners (HCP) also participated. Eleven participants were from Queensland and 10 from other Australian states. Interviews were undertaken at a time and place convenient for participants, either face-to-face $(n=10)$ or via telephone $(n=11)$. The interview duration averaged 64 minutes (range 42 to 84 minutes).

\section{Themes}

Three main themes emerged from the data and were interconnected: the pharmacist's current role, pharmacy as a health hub and barriers for expanding role(s) (Figure 1).

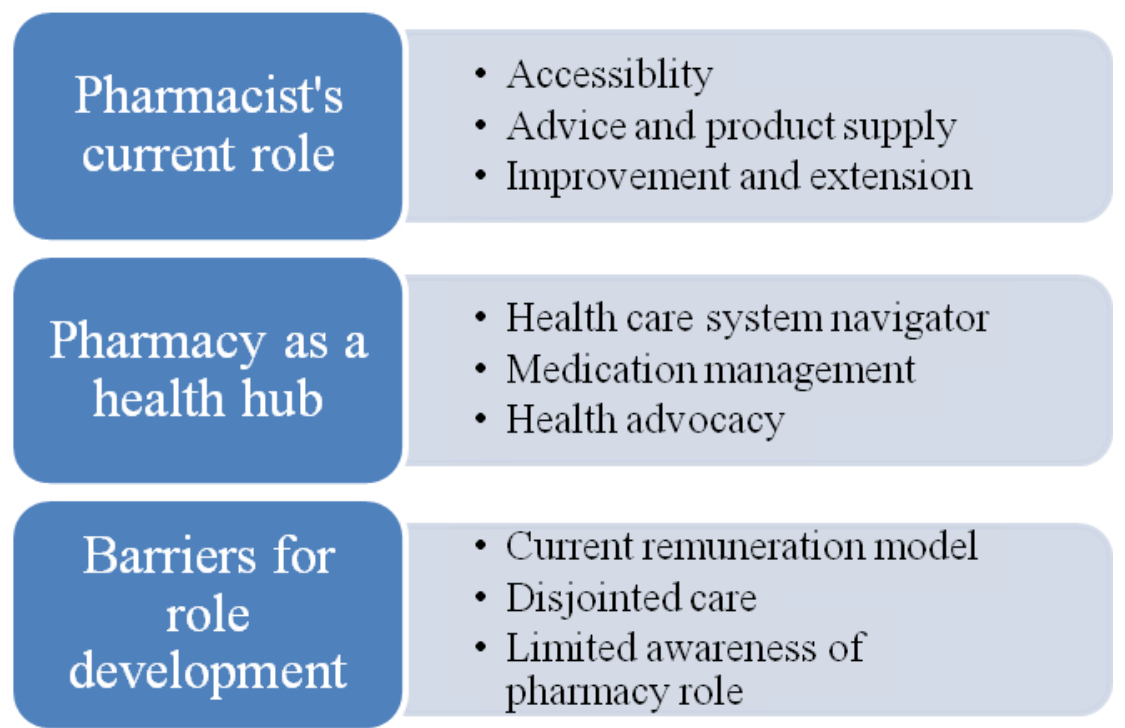

Figure 1: Key themes to emerge from the data 
Res Social Adm Pharm. 2012 Dec 4. pii: S1551-7411(12)00348-8.

doi: 10.1016/j.sapharm.2012.11.003. [Epub ahead of print]

\section{Pharmacist's current role}

Although the interviews were primarily focused on how community pharmacy and its staff can better assist consumers, all participants alluded to the current role that pharmacy plays in this area. Three key themes emerged in relation to this: accessibility, advice and product supply and improvement and extension of the pharmacist's role.

Some participants discussed that consumers viewed community pharmacists as highly accessible health professionals in terms of cost and location, particularly as there was no consultation fee involved. In addition, the approachability of pharmacists was discussed in terms of being easy to talk to, with participants acknowledging that some consumers may feel more comfortable talking to a pharmacist than a GP. One participant commented on the neutrality of the pharmacy as a health destination, where consumers could freely discuss concerns with the pharmacist without perceived risk of serious repercussions:

...I think there's a lot of personality that comes into play in your relationship with your doctor...I think that sometimes there's a fear of speaking openly.... I think that the pharmacy provides a neutral place where they can go in and they can say well; this is what they told me I have to take. Can you tell me how it goes? (CHO_13).

Pharmacists were also available for medication and health care advice without an appointment. This was emphasised by representatives from consumer organizations when discussing the difficulty in obtaining a doctor's appointment. However, interviewees also acknowledged that pharmacists were not accessible if they were predominantly focused on dispensing prescriptions: 
Res Social Adm Pharm. 2012 Dec 4. pii: S1551-7411(12)00348-8.

doi: 10.1016/j.sapharm.2012.11.003. [Epub ahead of print]

They're not. How can they be when they're two counters back, banging away on the keyboard. If you asked for the pharmacist, yeah, they'll come out when they're ready. But if they're busy, I'm too busy; I haven't got time (HCP_9).

Comments were consistent with the general view that the pharmacist's primary role was to dispense medications and provide medication advice. Some participants also discussed how pharmacists use their knowledge to clarify if a doctor's appointment was necessary and to provide non-prescription medication. However, health care professionals in particular perceived room for improvement in the pharmacist's medication supply and management role:

All I see is the pharmacy being a stockist of the products that I need to buy... They really don't provide any advice at all for my conditions. Most of the time I'm interacting with a pharmacy assistant who doesn't really have a clue... (HCP_09).

...the only thing that they ever ask you is, would you like the cheaper brand?...There's a huge opportunity to do it better (HCP_21).

This need for role improvement was also particularly expressed by a NGO representative, who raised concerns that pharmacists are inconsistent in providing medication information to consumers:

...even though there was mandated stuff brought in and they're paid money to do it...pharmacists are not complying with the provision of CMI [consumer medicines information] and that is critical if we're going to manage a chronic disease (CHO_14). 
Res Social Adm Pharm. 2012 Dec 4. pii: S1551-7411(12)00348-8.

doi: 10.1016/j.sapharm.2012.11.003. [Epub ahead of print]

However, the majority of participants discussed the value of more recent extensions to the traditional pharmacist supply role such as home medication reviews (HMRs) and dose administration aids for the community. Participants commented on how well pharmacists were providing such professional services, including medication deliveries. The following participant emphasizes the value of pharmacists in taking a holistic approach to a medication supply role:

So your pharmacists that deliver the drugs, I think are wonderful, because they're a different face coming into the house. They know who's in the house, and how the house is looking and how the person is looking.... (HA_17).

In consideration of the pharmacist's knowledge and training, the need for extending their role to assist in improving health care for consumers with chronic conditions was discussed in further detail:

...we're overtrained and undervalued... we probably are out of all of the health professions the most overtrained for what we currently get the opportunity to do (HCP_5).

\section{Pharmacy as a health hub}

A key theme to emerge in relation to extending the role of the pharmacist was the strong belief in the value of the community pharmacy becoming a health hub; a health care destination that involved more than just the provision of medication advice:

...it's not just about the drugs, it's about supporting them to lose weight...to do more exercise, to eat more proper foods and all the rest of it...this concept of being a health 
Res Social Adm Pharm. 2012 Dec 4. pii: S1551-7411(12)00348-8.

doi: 10.1016/j.sapharm.2012.11.003. [Epub ahead of print]

hub, being seen as what I call the health coach, needs to be part of the future of community pharmacy (HCP_7).

For the consumer to register with them [pharmacist], and work out a management care plan and have the pharmacist monitor their signs and their symptoms as part of their self-management plan (S1C_016).

This model of care could address some of the gaps in the health care system identified by participants:

...it can certainly be considered a kind of across the board issue, in terms of CALD [cultural and linguistically diverse] communities not knowing what is available and where to get that information (CHO_20_participant 2)

The services that clients are accessing are quite varied and disjointed...I think sometimes the GPs [general practitioner] become quite overwhelmed at the number of services that are out there and not knowing what they do. So it's difficult to get them to refer. (HCP_11).

The above quotes demonstrate that consumers need assistance in accessing non-government consumer health organizations and health care professionals, as the health system can be viewed as complex and disjointed. Therefore, participants identified that there was a need for pharmacists to assist consumers in the following areas, as attributes of a health hub concept: health care system navigation (signposting), medication management and health advocacy.

There was an acknowledgment amongst participants that consumers find it difficult to navigate the health system and to identify the support services and health professionals they 
Res Social Adm Pharm. 2012 Dec 4. pii: S1551-7411(12)00348-8.

doi: 10.1016/j.sapharm.2012.11.003. [Epub ahead of print]

individually require. Community pharmacies as accessible health care destinations could address this issue from two perspectives: a clinical triage role to other health care professionals and a more holistic approach by connecting consumers to non-government consumer health organizations for psychosocial support. This would include raising awareness of various health services and actively connecting consumers to these services within the health system.

...having them as a referral base to not just the GP, but to other ancillary services...(HCP_11).

There's a role that I think the community pharmacy can and should play in assisting in connecting people up. It's that point I mentioned before about navigating the system. I think we would strongly encourage community pharmacy to see itself as part of an interconnected system, and to play a role in connecting people with diabetes to the other things that might be useful for them (CHO_15).

...you know linking them with services, linking them with information and really raising awareness around things. Providing them with information about adherence to their medications... (CHO_19)

There was a strong emphasis that medication use reviews (other than home medicines reviews (HMRs), which are conducted by accredited pharmacists within the consumer's home) should be a service provided in the pharmacy as part of a health hub. This was identified as a strategy to address medication confusion, especially around generic versus branded medications. There was also consensus for pharmacists to continue to provide medication counselling, particularly for consumers taking multiple medications 
Res Social Adm Pharm. 2012 Dec 4. pii: S1551-7411(12)00348-8.

doi: 10.1016/j.sapharm.2012.11.003. [Epub ahead of print]

(polypharmacy) or those newly diagnosed:

...the pharmacist is ideally placed to be questioning the person about all of the medications that they are taking, so as they are filling a script for something, they should be having a bit of a chat to them... you know particularly older people polypharmacy is a huge deal (CHO_3).

... if I hear something from my doctor, but it didn't really register because I was kind of in shock and the doctor has given me a prescription and says, here go down to the pharmacy. I need the pharmacist then to be able to reinforce those messages (CHO_12).

Acting as a health advocate was also viewed as a natural extension of the medication management role, whereby the pharmacist can optimise the quality use of medicines whilst ensuring that consumers are satisfied with their overall health care. This can also encompass individualised and empowering care by supporting consumers to self-manage their condition(s).

...do I really need that medicine? If I do, what is the absolute minimum dose and the minimum amount of time I need to take that medicine...I think it's possible that pharmacists...could play a role in helping people ask those questions of their prescribers, and possibly could even advocate on behalf of people who come into the pharmacy and deal directly with the doctor (HA_18).

They really want the health professional, and this would equally apply to community pharmacy, to not just, say, focus on their biomedical measure like their blood glucose 
Res Social Adm Pharm. 2012 Dec 4. pii: S1551-7411(12)00348-8.

doi: 10.1016/j.sapharm.2012.11.003. [Epub ahead of print]

level, but how are they going and how are they coping and what are the issues for them and what are their needs? (S1C_015)

\section{Barriers for role expansion}

Participants acknowledged that there were structural and societal barriers facing community pharmacy in terms of becoming a health hub, with the current remuneration model identified as the over-arching barrier.

Participants expressed that pharmacists are concerned with the supply of commercial products because the pharmacy is primarily a business, and the current environment typically had unsuitable space for professional services such as counselling. This was particularly discussed by participants not representing a consumer organization:

...there's that commercial aspect of it. That's a priority and that's important for them.

They're not necessarily government funded to come out and discuss case by case issues (HCP_11).

The lack of privacy was also discussed as an influential factor as to whether consumers would seek advice from community pharmacy. Innovative practitioners and health care professional organisation representatives also emphasised that in the past, there was no real push to change the current pharmacy model, which focused on product supply and prescription volume. One participant highlighted the difficulty in changing the culture:

....I think it's been too easy to make money the other way. I think change is hard. I think it takes courage... and I think there's some things that pharmacists are frightened of (HCP_021). 
Res Social Adm Pharm. 2012 Dec 4. pii: S1551-7411(12)00348-8.

doi: 10.1016/j.sapharm.2012.11.003. [Epub ahead of print]

Further to this, there was also discussion about the unsustainability of community pharmacy as it stands. The recent regulations requiring price disclosure in Australia ${ }^{28}$ and a potential decline in revenue for the supply of generic prescription medications may be the catalyst needed for change:

....people are starting to feel the financial pressure with the retail model; because the government has made reforms around the PBS [Pharmaceutical Benefits Scheme] and the remuneration model for purely supply... (HCP_5).

Although the various attributes of a health hub destination were discussed by participants, there was also acknowledgment of the simple need for the pharmacist to step out of the dispensary to engage and become more proactive with health consumers. One participant also discussed the possibility of utilising pharmacy assistants to provide medication education to consumers after further training in this role:

...as long as the pharmacy assistants...had good training and they had the support of the pharmacist... to be doing it as part of their role, I think actually they could still do quite a goodjob (CHO_8).

Another barrier raised by participants was the lack of coordinated care between pharmacists and other health care professionals. One interviewee attributed this to the current pharmacy model where community pharmacists worked in a silo and there was limited opportunity to contribute to multidisciplinary teams: 
Res Social Adm Pharm. 2012 Dec 4. pii: S1551-7411(12)00348-8.

doi: 10.1016/j.sapharm.2012.11.003. [Epub ahead of print]

I think pharmacy, especially community pharmacy, very much works in a silo. It's not all their fault...it's the way the system sort of has developed....There needs to be more information flow between health professionals, including pharmacists... (HCP_21).

A lack of communication or engagement with other health care professionals may negatively impact on their perception of the role that pharmacists can play. The implementation of personally controlled electronic health records, which was recently launched in Australia ${ }^{29}$, was identified as one way to improve this communication and delivery of health care by interviewees.

Interviewees acknowledged that a challenge facing the pharmacy profession was that some consumers were unsure of what pharmacists could do other than supply medication. Consumers lacked the confidence to ask for medication advice and did not want to be seen as a bother:

...I think the key area about managing the conditions is for consumers to feel confident, have the knowledge and the skills that it's okay to go in and ask for a review of your medicines by the pharmacist....(CHO_14).

Although consumers needed to be more proactive in seeking help, it was suggested that pharmacists should promote their professional skills and engage further with consumers to address this barrier.

\section{Discussion}

This study set out to explore the perspectives of non-government consumer health 
Res Social Adm Pharm. 2012 Dec 4. pii: S1551-7411(12)00348-8.

doi: 10.1016/j.sapharm.2012.11.003. [Epub ahead of print]

organizations and health advocates as to how community pharmacy can better assist consumers with chronic illness. Overall the core finding of this study was the potential for community pharmacies to move beyond medication supply and become a health hub destination that assisted consumers with chronic conditions across three key domains: health care system navigation, medication management and eventually, health advocacy. Although the shift for pharmacy to provide professional health services has been emphasised both nationally ${ }^{30}$ and internationally, ${ }^{7,31,32}$ the notion that they could provide consumer support to navigate the health system and act as health advocates broadens the patient-centred approach to care. Barriers associated with an extended health care role were also discussed and reinforce those reported in the literature. ${ }^{4,33-35}$

Participants emphasised the accessibility of pharmacy, because many consumers use the pharmacy as a primary point of contact. ${ }^{4}$ Furthermore, pharmacies were identified as a neutral health care destination, providing independent advice and support to consumers. However, the importance of privacy and confidentiality to deliver professional services was emphasised, with participants agreeing that it was imperative for pharmacy to designate appropriate areas for this purpose. This is in line with existing research; lack of privacy and the capacity for confidential conversations are potential barriers for community pharmacists to better assist consumers with new services or medication and health information counselling. ${ }^{32,36}$ Considering that some chronic conditions are sensitive in nature, or consumers may regard their condition/s as such, privacy and confidentiality are important matters.

Innovative practitioners and representatives of health professional organizations also acknowledged that pharmacists are underutilised health professionals, a finding which has 
Res Social Adm Pharm. 2012 Dec 4. pii: S1551-7411(12)00348-8.

doi: 10.1016/j.sapharm.2012.11.003. [Epub ahead of print]

been previously reported. ${ }^{18,37}$ Furthermore, it was evident that there is a current disconnect in the health system, with participants emphasizing the difficulties for consumers to find the resources, support and services they need. This was identified as a particular problem when first diagnosed with a condition. Furthermore, this gap in the health system was recently highlighted in an Australian study that also interviewed community based service providers. ${ }^{24}$ Our study identified that pharmacists are ideally placed to address this disconnect in the health system by navigating (or signposting) consumers from two perspectives: to other health professionals in a clinical triage role and to non-government consumer health organizations, thereby providing a more holistic approach to care. This can be viewed as complementary to the pharmacist's current role in the provision of medication advice. As consumers may have difficulty recalling information from medical consultations, and the degree of information understood at initial diagnosis may be reduced due to increased emotional status ${ }^{38}$ the pharmacist's role in re-capping information is critically important. Our findings corroborate research, which reports that pharmacists are often sought to reinforce or clarify directions. ${ }^{37}$ GPs have also acknowledged that due to time constraints, the community pharmacist may be better placed to reinforce medication information. ${ }^{32}$

However, participants also acknowledged that there were aspects of their current role that pharmacists needed to improve on, such as the provision of consumer medicines information (CMI) leaflets. This is not the first call for pharmacists to improve this service. ${ }^{17,44}$ Low rates of CMI leaflet supply by community pharmacists have been identified, particularly for repeat prescription items where the consumer had previously used the medication. ${ }^{44}$ If community pharmacies are to become a health hub destination, it is vital that pharmacists have the time to provide CMIs and medication counselling tailored to the needs of the customer, as well as any additional information (e.g., health promotion). 
Res Social Adm Pharm. 2012 Dec 4. pii: S1551-7411(12)00348-8.

doi: 10.1016/j.sapharm.2012.11.003. [Epub ahead of print]

Community pharmacists in Great Britain and New Zealand (NZ) have extended their contribution by conducting medication use reviews (MURs). ${ }^{32,39}$ This has been identified as a positive role for community pharmacists by NZ GP's, with the pharmacist's medication knowledge being utilised to increase patient understanding and medication adherence. ${ }^{32}$ Therefore, the pharmacist is a suitable health professional to emphasise and tailor counselling for the consumer and participants in our study suggested that pharmacists could extend their current role by conducting medication reviews. The information gathered from these consultations could result in the pharmacist advocating on behalf of the person and ensuring the quality use of medications. Indeed, the novel concept of pharmacists undertaking a health advocacy role was also identified in a recent study exploring the integration of Australian pharmacist in GP practices. ${ }^{40}$ This role is consistent with current professional practice standards, which states that the pharmacist 'accepts responsibility for advocating on behalf of consumers consistent with the professional role and expertise of the pharmacist. ${ }^{41}$ Although medication reviews such as HMRs are conducted by accredited pharmacists in Australia, it is an opportune time for community pharmacists to progress towards a health advocacy role by introducing medication reviews such as the MedsCheck program into their practice. ${ }^{42}$ This service is similar to MURs, with pharmacists remunerated for reviewing and discussing the consumer's medications, providing medication and lifestyle related education and developing an individual action plan. ${ }^{43}$ Pharmacists are required to designate a private area for MedsCheck consultations and ensure they have the time to perform them. ${ }^{43}$ The importance of changes to policy and the practice environment in order for MURs to reach their full potential in improving consumer understanding of their medications has been highlighted in a recent study. ${ }^{39}$

Although there was discussion about what a health hub should involve, less 
Res Social Adm Pharm. 2012 Dec 4. pii: S1551-7411(12)00348-8.

doi: 10.1016/j.sapharm.2012.11.003. [Epub ahead of print]

information was provided by participants as to how the profession can move towards this goal. Furthermore, participants identified that there were multiple barriers facing pharmacists to improve care and become a health hub, including the current model of practice. It was acknowledged by an innovative health care professional that some Australian community pharmacists may be anxious of change and are supportive of the current model, a finding consistent with the literature. ${ }^{34}$ Similarly, this has been reflected in New Zealand research; pharmacists recognised the need to embrace change and incorporate further services into their role but were still supportive of the status quo. ${ }^{45}$ Given the challenges facing pharmacists to expand their role(s), the current tasks undertaken by pharmacy assistants may be easier to change. One interviewee in our study promoted the idea of utilising pharmacy assistants to provide further information, as long as they were trained appropriately. We propose that the current strain placed on the pharmacist's time could potentially be reduced if pharmacy assistants extended their roles. Alternatively, mandatory accreditation of pharmacy technicians, as seen in Great Britain, ${ }^{46}$ would allow technicians to focus on dispensing tasks, enabling the pharmacist to deliver other health services.

Of concern is that non-government consumer health organizations perceived that some consumers may lack the confidence to seek the pharmacist's advice. Furthermore, they may be unaware of the breadth of the pharmacist's expertise beyond the supply of medication, which is consistent with existing knowledge. ${ }^{12,13,18,19,47}$ Our study confirms that further promotion of the pharmacist's role is needed for the entire community. However, a recent paper ascertained that Scottish consumers were inclined to seek professional services from their GP, and an increase in service uptake did not follow on from an increased knowledge of pharmacy services. ${ }^{47}$ The authors proposed that this could be due to: a level of uncertainty of pharmacists training, privacy concerns, and perception of a better relationship 
Res Social Adm Pharm. 2012 Dec 4. pii: S1551-7411(12)00348-8.

doi: 10.1016/j.sapharm.2012.11.003. [Epub ahead of print]

with their GP who has a broader understanding of their medical history ${ }^{47}$. However, there are notable differences between the Australian and British health systems; further research is needed to determine if these results apply in the Australian context. For example, there is no GP consultation fee and consumers predominantly register with one GP surgery in Great Britain, which could promote rapport and trust development. The pharmacist is more accessible to Australian consumers who are required to make a co-payment to see a non-bulk billing GP. The authors suggested that to increase the utilisation of pharmacy services, pharmacists need to obtain support from GPs. ${ }^{47}$ As GPs have raised concerns about fragmentation of care resulting from consumers alternatively accessing health services via pharmacies, ${ }^{32}$ it is critical that pharmacists engage collaboratively with the primary care team. ${ }^{18} \mathrm{We}$ also recommend that pharmacists discuss the provision of services within the pharmacy setting and communicate with the consumer's network of health care professionals as noted in the interviews. A collaborative relationship between primary care providers is necessary, and it has been acknowledged that a team-based approach is an important attribute of the Chronic Care Model. ${ }^{48}$ In addition, there is the potential for e-health records to improve the co-ordination of services. ${ }^{34}$ When implementing pharmacy services, the current study suggests that this collaborative approach should extend to non-government consumer health organizations, as consumers with chronic conditions will often seek their advice and support. These organizations can advise and refer them to their local pharmacy and vice versa.

The majority of participants who commented on remuneration identified that this should occur for pharmacists to provide further professional services. Although participants from non-government consumer health organizations appeared to have limited knowledge of the pharmacy system (i.e., more system/professional barriers were discussed by health care 
Res Social Adm Pharm. 2012 Dec 4. pii: S1551-7411(12)00348-8.

doi: 10.1016/j.sapharm.2012.11.003. [Epub ahead of print]

professionals), some participants still identified a need for remuneration. A recent international systematic review identified that remuneration was not a barrier for the provision of public health services such as health promotion and smoking cessation counselling. ${ }^{4}$ However, others have identified that remuneration is a facilitator to practice change ${ }^{49}$, indicating that remuneration may be a requirement for more extensive clinical services such as medication reviews and counselling. This is emphasised by the pharmacy practice incentives funded by the Australian Government Department of Health and Ageing since $2011 .^{50}$ There are new opportunities for community pharmacists to be remunerated for services currently delivered in pharmacy (e.g., dose administration aids, staged supply, community services support and clinical interventions) and novel initiatives (e.g., primary health care and working with others). ${ }^{50}$ These initiatives indicate an exciting time for community pharmacy in Australia, signifying that the health hub concept is a vision of the not too distant future.

\section{Limitations}

We sought a variety of opinions from representatives of key organizations; however we employed purposive sampling and obtained a small number of participants, including only health professionals representing the disciplines of pharmacy and medicine. As such, the findings may not reflect the views of all non-government consumer health organizations, health professionals or health advocates. Furthermore, no distinction was made between individual practitioners and those representing organizations when organizing the data and extensive analysis between the three groups could not be conducted. As an exploratory study, an aim was to identify general themes to inform the development of an interview guide. Therefore, comparisons between the groups were not made. Considering the lack of literature in this area, further research is needed. Although there is an increased risk of bias 
Res Social Adm Pharm. 2012 Dec 4. pii: S1551-7411(12)00348-8.

doi: 10.1016/j.sapharm.2012.11.003. [Epub ahead of print]

due to the reliance of self-reported data from participants when representing whole organizations, this was identified as the most effective way to collect the information. As some of the interviewees were located interstate or preferred to conduct the interview by phone, the lack of non-verbal cues may have adversely influenced the data collection process.

\section{Conclusion}

This study confirms the need for pharmacists to extend their health care role in chronic illness management; a need emphasised by professional pharmacy organizations over the last decade. Pharmacists can better support consumers with chronic illness by assisting them to navigate a disconnected health system in two ways: via a clinical triage role by referring consumers to health care professionals, and recommending non-government consumer health organizations with an emphasis on a holistic approach to care. Furthermore, participants proposed for community pharmacists to ultimately extend their roles in medication management and advice towards health advocacy.

While funded practice initiatives have been recently introduced by the Australian government, further support and policy guidance is needed if community pharmacists are to incorporate these roles into daily practice. Furthermore, the pharmacy profession needs to actively promote their expertise and roles to consumers, and collaboratively work with health care professionals and non-government consumer health organizations. Additionally, there is a clear need for investigation into how community pharmacy can address the barriers identified by interviewees. Whilst participants were clear about the major issues for change, they were less clear about the 'how to' change. Although multiple challenges arose from the interviews, this study demonstrates that there is a strong belief that community pharmacy can proceed in the right direction by becoming a health hub destination of the future. 
Res Social Adm Pharm. 2012 Dec 4. pii: S1551-7411(12)00348-8.

doi: 10.1016/j.sapharm.2012.11.003. [Epub ahead of print]

\section{Acknowledgements}

We are grateful to all participants who gave their time and shared their views with us.

In addition, we would like to thank Dr Shane Scahill for providing feedback on the manuscript.

\section{Funding}

This project is funded by the Australian Government Department of Health and Ageing as part of the Fifth Community Pharmacy Agreement Research and Development Program managed by The Pharmacy Guild of Australia. 
Res Social Adm Pharm. 2012 Dec 4. pii: S1551-7411(12)00348-8.

doi: 10.1016/j.sapharm.2012.11.003. [Epub ahead of print]

\section{Table 1: Interview guide regarding community pharmacy \#}

How do your members currently use community pharmacy to help them manage their chronic illness(s)?

What is the [organization/individual] perspective on the role that community pharmacies currently have in the management of consumers with chronic illness(s)?

Can you describe the types of services that community pharmacy currently provide for health consumers to support them to manage their chronic illness(s)?

Can you tell me how the role of community pharmacy in assisting consumers with chronic illness(s) has evolved?

Do your members comment about problems or concerns that consumers with chronic illness(s) have with their medication(s) for their chronic illness(s)?

What are some of the main problems or concerns that you think consumers with chronic illness(s) have?

How could community pharmacy help your members to manage their chronic illness(s)?

What is [insert organization/individual]'s perspective on the role that community pharmacy could have in the management of consumers with chronic illness in the future?

What types of services do you see community pharmacy providing in the future to better support health consumer to manage their chronic illness(s)?

What issues do you think community pharmacy might face in moving towards new models of care or services to support consumers with management of chronic illness(s)?

\footnotetext{
${ }^{\#}$ These questions are a guide only. The interview framework was altered for each participant depending on their position and background
} 
Res Social Adm Pharm. 2012 Dec 4. pii: S1551-7411(12)00348-8.

doi: 10.1016/j.sapharm.2012.11.003. [Epub ahead of print]

\section{References}

1. World Health Organization. (2011). Noncommunicable diseases country profiles 2011.

2. Australian Bureau of Statistics. National Health Survey: Summary of Results, 2007-2008 (Reissue); 2010. Available at:

http://www.abs.gov.au/ausstats/abs@.nsf/Latestproducts/4364.0Main\%20Features220072008\%20\%28Reissue $\% 29$ ?opendocument $\&$ tabname $=$ Summary $\&$ prodno $=4364.0 \&$ issue $=200$ 7-2008\%20\%28Reissue\%29\&num=\&view $=$. Accessed 15/11/2012.

3. Australian Institute of Health and Welfare. Australia's Health 2010; 2010. Available at: http://www.aihw.gov.au/publication-detail/?id=6442468376\&tab=2 Accessed 15/11/2012.

4. Eades C, Ferguson J, O'Carroll R. Public health in community pharmacy: A systematic review of pharmacist and consumer views. BMC Public Health. 2011; 11:582.

5. The Pharmacy Guild of Australia. (2010). The Roadmap: The Strategic Direction for Community Pharmacy. Available at: http://www.guild.org.au/iwovresources/documents/The Guild/PDFs/News\%20and\%20Events/Publications/The\%20Road map/Roadmap.pdf Accessed 15/11/2012.

6. Clark A, Roughead L. Pharmacist perspectives on managing older patients with multiple chronic conditions. Aust Pharm. 2012:148-153.

7. Lamberts EJF, Bouvy ML, van Hulten RP. The role of the community pharmacist in fulfilling information needs of patients starting oral antidiabetics. Res Soc Admin Pharm. 2010; 6:354364.

8. George P, Molina J, J C, SC C, BP L. The evolving role of the community pharmacist in chronic disease management - a literature review. Ann Acad Med Singapore. 2010; 39:861-867.

9. Rigby D. Collaboration between doctors and pharmacists in the community. Aust Prescriber.2010; 33:191-193.

10. Pharmaceutical Society of Australia. (2010). Issues Paper on the Future of Pharmacy in Australia. Available at:

http://careers.curtin.edu.au/data/shared/documents/faculty specific resources/health sci ences/psa future of pharmacy2010.pdf Accessed 15/11/2012.

11. Teh R, Chen T, Krass I. Consumer perspectives of pharmacist-delivered healtn information and screening services. Int J Pharm Prac. 2001; 9:261-267.

12. Anderson C, Blenkinsopp A, Armstrong M. Feedback from community pharmacy users on the contribution of community pharmacy to improving the public's health: a systematic review of the peer reviewed and non-peer reviewed literature 1990-2002. Health Expect. 2004; 7:191-202.

13. Taylor J, Krska J, Mackridge A. A community pharmacy-based cardiovascular screening service: views of service users and the public. Int J Pharm Prac. 2012: DOI:10.1111/j.20427174.2012.00190.x.

14. Young CE, Mutch AJ, Boyle FM, Dean JH. Investigating referral pathways from primary care to consumer health organisations. Aust J Prim Health. 2010; 16:260-267.

15. Sav A, McMillan S, Kendall E, Kelly F, Whitty J, King M, Wheeler A. Treatment burden among people with chronic illness: What are consumer health organisations saying? Chronic Illness 2012; DOI: 10.1177/1742395312463411.

16. Mott K, Eltridge F, Gilbert A, March G, Lawson T, Vitry A, Rao D, Weir D, Wade D, B. A. (2005). Consumer experiences, needs and expectations of community pharmacy. Available at: http://www.guild.org.au/sites/The Guild/tab-

Pharmacy Services and Programs/Research and Development/Third\%20Agreement/2005 -501.page Accessed 15/11/2012.

17. Dunphy D, Palmer I, Benrimoj S, Roberts A. (2005). The final report of the change management and community pharmacy project. Available at:

http://www.guild.org.au/sites/The Guild/tab- 
Res Social Adm Pharm. 2012 Dec 4. pii: S1551-7411(12)00348-8.

doi: 10.1016/j.sapharm.2012.11.003. [Epub ahead of print]

Pharmacy Services and Programs/Research and Development/Third\%20Agreement/2003 -530.page Accessed 15/11/2012.

18. Um IS, Armour C, Krass I, Gill T, Chaar BB. Consumer perspectives about weight management services in a community pharmacy setting in NSW, Australia. Health Expect. 2012:1-14.

19. Perepelkin J. Public opinion of pharmacists and pharmacist prescribing. Can Pharm J. 2011; 144:86-93.

20. Peterson GM, Jackson SL, Hughes JD, Fitzmaurice KD, Murphy LE. Public perceptions of the role of Australian pharmacists in cardiovascular disease. J Clin Pharm Ther. 2010; 35:671-

677.

21. Australian Government Department of Health and Ageing. (2010). Building a 21st Century Primary Health Care System. Australia's First National Primary Health Care Strategy.

Available at:

http://www.yourhealth.gov.au/internet/yourhealth/publishing.nsf/Content/CA2578620005 CE1DCA257729001BACBD/\$File/6552\%20NPHC\%201205.pdf Accessed 15/11/2012.

22. Sim J, Wright C. Research in health care: concepts, designs and methods. United Kingdom: Stanley Thornes Ltd, 2000.

23. National Health Priority Action Council (NHPAC). National Chronic Disease Strategy; 2006. Available at:

http://www.health.gov.au/internet/main/publishing.nsf/content/7E7E9140A3D3A3BCCA25 7140007AB32B/SFile/stratal3.pdf Accessed 15/08/2012.

24. Longman JM, Singer JB, Gao Y, Barclay LM, Passey ME, Pirotta JP, Heathcote KE, Ewald DP, Saberi V, Corben P, Morgan GG. Community based service providers' perspectives on frequent and/or avoidable admission of older people with chronic disease in rural NSW: a qualitative study. BMC health services research name. 2011; 11:265.

25. Pope C, Zieblan S, Mays N. Analysing qualitative data. In: Pope C, Mays N (eds) Qualitative research in health care. Oxford: Blackwell Publishing Ltd,2006 63 - 81.

26. Braun V, Clarke V. Using thematic analysis in psychology. Qual Res Psych. 2006; 3:77-101.

27. Guest G, Bunce A, Johnson L. How Many Interviews Are Enough?: An Experiment with Data Saturation and Variability. Field Methods. 2006; 18:59-82.

28. de Boer R. Health - Pharmaceuticals and pharmacy; 2011. Available at: http://www.aph.gov.au/About Parliament/Parliamentary Departments/Parliamentary Libr ary/pubs/rp/BudgetReview201011/HealthPharmaceuticals. Accessed 15/08/2012.

29. Australian Government Department of Health and Ageing. eHealth; 2012. Available at: http://www.yourhealth.gov.au/internet/yourhealth/publishing.nsf/Content/theme-ehealth. Accessed 15/08/2012.

30. Feletto $\mathrm{E}$, Wilson L, Roberts $\mathrm{A}$, Benrimoj S. Flexibility in community pharmacy: a qualitative study of business models and cognitive services. Pharm World Sci. 2010; 32:130-138.

31. Dobson RT, Taylor JG, Henry CJ, Lachaine J, Zello GA, Keegan DL, Forbes DA. Taking the lead: Community pharmacists' perception of their role potential within the primary care team. Res Soc Admin Pharm. 2009; 5:327-336.

32. Hatah E, Braund R, Duffull S, Tordoff J. General practitioners' perceptions of pharmacists' new services in New Zealand. Int J Clin Pharm. 2012; 34:364-373.

33. Krska J, Veitch GBA. Perceived factors influencing the development of primary care-based pharmaceutical care in Scotland. Int J Pharm Prac. 2001; 9:243-252.

34. Mak VSL, Clark A, Poulsen JH, Udengaard KU, Gilbert AL. Pharmacists' awareness of Australia's health care reforms and their beliefs and attitudes about their current and future roles. Int J Pharm Prac. 2012; 20:33-40.

35. Agomo CO. The role of community pharmacists in public health: a scoping review of the literature. J Pharm Health Serv Res. 2012; 3:25-33. 
Res Social Adm Pharm. 2012 Dec 4. pii: S1551-7411(12)00348-8.

doi: 10.1016/j.sapharm.2012.11.003. [Epub ahead of print]

36. Hill P, Dowse R. Cognitive pharmaceutical services and the community pharmacist: are South African patients receiving them and are they willing to pay? Int J PharmPrac. 2007; 15:201208.

37. Tarn DM, Paterniti DA, Wenger NS, Williams BR, Chewning BA. Older patient, physician and pharmacist perspectives about community pharmacists' roles. Int J Pharm Prac. 2012;

38. Ong LML, de Haes JCJM, Hoos AM, Lammes FB. Doctor-patient communication: A review of the literature. Soc Sci Med. 1995; 40:903-918.

39. Latif A, Pollock K, Boardman HF. The contribution of the Medicines Use Review (MUR) consultation to counseling practice in community pharmacies. Patient Educ Couns. 2011; 83:336-344.

40. Freeman C, Cottrell WN, Kyle G, Williams I, Nissen L. Integrating a pharmacist into the general practice environment: opinions of pharmacist's, general practitioner's, health care consumer's, and practice manager's. BMC health serv res. 2012; 12:229.

41. Pharmaceutical Society of Australia. (2010, June 2010). Professional Practice Standards Version 4 - June 2010. Available at: http://www.psa.org.au/download/standards/professional-practice-standards-v4.pdf Accessed 15/08/2012.

42. The Australian Department of Health and Ageing, The Pharmacy Guild of Australia. About MedsCheck and Diabetes MedsCheck; 2012. Available at: http://www.5cpa.com.au/sites/5CPA/Initiatives/Medication Management/MedsCheck and Diabetes MedsCheck/About\%20MedsCheck.page. Accessed 15/08/2012.

43. The Australian Department of Health and Ageing, The Pharmacy Guild of Australia. MedsCheck and Diabetes MedsCheck Service Checklist; 2012. Available at: http://www.5cpa.com.au/iwovresources/documents/5CPA/Initiatives/Medication Management/MedsCheck and Diabete s MedsCheck/MCDMCModel v0.6 206456 5.PDF Accessed 15/08/2012.

44. Puspitasari HP, Aslani P, Krass I. Pharmacists' and consumers' viewpoints on counselling on prescription medicines in Australian community pharmacies. Int J Pharm Prac. 2010; 18:202208.

45. Scahill S, Harrison J, Sheridan J. Pharmacy under the spotlight: New Zealand pharmacists' perceptions of current and future roles and the need for accreditation. Int J PharmPrac. 2010; 18:59-62.

46. Schafheutle El, Smith C, Cutts C, Higginson PJ, Noyce PR. Pharmacy technicians' views of learning and practice implementation. Int J Pharm Prac 2012; 20:141-147.

47. Gidman W, Ward P, McGregor L. Understanding public trust in services provided by community pharmacists relative to those provided by general practitioners: a qualitative study. BMJ Open. 2012; 2

48. Dey RM, de Vries MJW, Bosnic-Anticevich S. Collaboration in chronic care: unpacking the relationship of pharmacists and general medical practitioners in primary care. Int J Pharm Prac. 2011; 19:21-29.

49. Roberts AS, Benrimoj SI, Chen TF, Williams KA, Hopp TR, Aslani P. Understanding practice change in community pharmacy: a qualitative study in Australia. Res Soc Admin Pharm. 2005; 1:546-564.

50. Australian Government Department of Health and Ageing, The Pharmacy Guild of Australia. (2012). Program Specific Guidelines: Pharmacy Practice Incentives (PPI). Available at: http://www.5cpa.com.au/iwovresources/documents/5CPA/Initiatives/PPI/Program Specific Guidelines/Pharmacy\%20Prac tice\%20Incentives\%20Program\%20Specific\%20Guidelines\%20(Febuary\%202012).pdf Accessed 15/08/2012. 